Revista Destaques Acadêmicos, Lajeado, v. 12, n. 3, 2020. ISSN 2176-3070

DOI: http://dx.doi.org/10.22410/issn.2176-3070.v12i3a2020.2602

http://www.univates.br/revistas

\title{
RELAÇÕES ECOLÓGICAS E CUIDADOS COM O MEIO AMBIENTE VIABILIZADOS PELA CONSTRUÇÃO DE UM TERRÁRIO EM AULAS DE CIÊNCIAS COMO AÇÃO DE EDUCAÇÃO AMBIENTAL
}

\author{
Monica Strege Médici ${ }^{1}$, Marcelo Franco Leão ${ }^{2}$
}

\begin{abstract}
Resumo: Ao analisar o cenário mundial, percebemos o momento crítico que vivemos acerca dos impactos ambientais, pois as atividades antrópicas tem comprometido significativamente a qualidade do ambiente. As consequências estão cada vez mais visíveis na atualidade, manifestadas por meio de fenômenos naturais, tais como: enchentes, derretimento das geleiras polares, desertificação do solo, escassez de água potável, dentre outros aspectos. Este texto tem como objetivo relatar a construção de um terrário e as percepções dos estudantes de uma turma do Ensino Fundamental sobre as relações ecológicas possibilitadas pela atividade e os cuidados necessários com o meio ambiente para minimizar os impactos ambientais provocados pelas atividades humanas. O estudo desenvolvido no $2^{\circ}$ semestre de 2019 com 28 estudantes do $7^{\circ}$ ano do Ensino Fundamental de uma escola pública mato-grossense localizada em Vila Rica/ MT. Para coletar os dados foi utilizado um questionário de 12 perguntas mistas, que possibilitou identificar tanto concepções conceituais sobre o assunto, quanto avaliação da atividade realizada, além das relações que percebem sobre as ações humanas e a natureza. Logo, a atividade proporcionou que externassem suas percepções sobre o assunto e estabelecessem relações que remetem os cuidados necessários com o meio ambiente.
\end{abstract}

Palavras-chave: Ecologia. Impactos ambientais. Meio ambiente.

1 Graduação em Licenciatura em Ciências Biológicas e Bacharel em Ecologia (Centro Universitário de Várzea Grande). Especialização em Ensino de Biologia (Universidade Candido Mendes). Professora efetiva na Escola Estadual Professora Maria Esther Peres onde ministra as disciplinas de ciências e biologia para o Ensino Fundamental e Médio. Membro do Grupo de Pesquisa Ensino de Ciências e Matemática no Baixo Araguaia (EnCiMa).

2 Graduação em Química Licenciatura Plena (UNISC) e em Licenciatura em Física (UNEMAT). Especialização em Orientação Educacional (DOM ALBERTO) e em Relações Raciais e Educação na Sociedade Brasileira (UFMT). Mestrado em Ensino (UNIVATES) e Doutorado em Educação em Ciências: Química da Vida e Saúde (UFRGS). Professor de Química no Departamento de Ensino do IFMT Campus Confresa. Membro do Grupo de Pesquisa Ensino de Ciências e Matemática no Baixo Araguaia (EnCiMa). 


\section{INTRODUÇÃO}

Atualmente, a preocupação com o desequilíbrio ambiental tem sido foco de diversos debates em nível mundial, tendo em vista a construção de uma política ambiental voltada para o desenvolvimento sustentável, no qual a preservação ambiental possa andar aliada ao desenvolvimento econômico. De acordo com Weisman (2014, p. 34), é preciso refletir sobre os seguintes questionamentos: "Quantas pessoas a terra pode abrigar? Como estas pessoas comem? Qual a quantidade de água as mesmas precisam para sobreviver? E onde obtém água e alimento? O planeta Terra suportará até quando o extrativismo de recursos naturais?".

O autor supracitado sugere que tais questionamentos sejam respondidos por meio de uma visão holística do planeta, considerando a vastidão do território quando nosso olhar está voltado para o território geográfico brasileiro temos uma heterogeneidade regional em termos de utilização dos recursos naturais e a manutenção de sobrevivência humana. De acordo com os dados do Instituto Brasileiro de Geografia e Estatística - IBGE (2016), as principais atividades econômicas brasileiras são: a agropecuária, a indústria e a prestação de serviços. Estes dados são importantes para repensarmos o que abordar nas aulas de ciências e propor medidas que minimizem os impactos ambientais.

Nesse sentido, a escola precisa contribuir na formação dos estudantes para emergir uma nova visão do sentido de ensinar e aprender, oportunizando a eles a construção de uma visão abrangente e consciente em relação ao uso de recursos naturais. Assim, as atividades propostas na escola necessitam ser voltadas para a sensibilização dos estudantes para que compreendam a dinâmica do meio ambiente.

Doravante, é fundamental que a escola insira em seu currículo, sempre que possível, a Educação Ambiental (EA). De acordo com Grzebieluka, Kubiak e Schiller (2014), a EA compreende as práticas pedagógicas voltadas para formar cidadãos conscientes, para que eles consigam tomar algumas decisões que possam contribuir positivamente. Com vistas a construir uma sociedade mais sustentável, pensando no seu meio, voltados a coletividade. Neste sentido, entende-se que é por meio de ações de EA que a escola formará cidadãos críticos preparados para viverem sob uma nova visão de sociedade.

Haja vista que a escola é um espaço no qual as discussões são difundidas a um grande contingente populacional, inserir esta temática é de suma importância para auxiliar os estudantes a construírem uma consciência global sobre as questões relacionadas ao meio ambiente para então assumir posições alinhadas com o desenvolvimento sustentável.

De acordo com Leonard (2011, p. 16): "Nada é mais importante para os seres humanos que uma biosfera economicamente funcional que a vida na terra". Ou seja, é preciso considerar o planeta terra como o único lugar habitável do universo todos os seres vivos dependem da mesma. Nessa linha de 
pensamento, é necessário acreditar que a EA desempenhe seu papel na escola conclamando a cada indivíduo para sua responsabilidade em defesa do planeta e da perpetuação de sua própria espécie e de todos os demais seres vivos.

As lideranças mundiais debruçam-se sobre o tema há décadas e pouco tem avançado neste sentido, o que deixa clara a ineficiência de implantações de políticas ambientais no sentido de economizar a natureza, tema consolidado por Ricklefs (2016), no livro "A Economia da Natureza", que apresenta cada sistema ecológico como um subconjunto de um nível maior, tal que os diferentes tipos de sistemas ecológicos formam uma hierarquia. Surge então os seguintes questionamentos: Como este tema pode ser discutido no ambiente escolar? E qual sua importância no âmbito pedagógico?

São inúmeras as estratégias que podem ser utilizadas no intuito de sensibilizar os estudantes que o planeta Terra é na verdade a nossa casa e que por isso necessita cuidado, dentre as quais optamos pela construção de um terrário devido aliar reflexões conceituais com situações reais.

Acreditamos que ao utilizar o terrário como estratégia e ação de EA seja possível compreender as interações entre o meio biótico e abiótico em uma perspectiva práticas. Como apontam Delizoicov, Angottie Pernambuco (2009) o ensino de Ciências Naturais requer um planejamento voltado para estratégias praticas que sejam capazes de estimular estudante a produzir e ressignificar o conhecimento.

O terrário é uma estratégia didática viável por ser objeto um pedagógico de fácil confecção e com baixo custo. Dessa forma, a atividade pode ser desenvolvida com facilidade, no sentido de estbelecer uma relação entre as ações humanas e suas consequências no desequilíbrio ambiental. Contudo, há uma intrínseca relação entre a existência humana e a preservação ambiental, fato que nos permite dimensionar a relevância da experiência desenvolvida.

Por considerar a escola um espaço privilegiado para promoção da aprendizagem fortalecendo valores e atitudes é que se propôs o desenvolvimento dessa ação educativa. Dado o exposto, esse texto tem como objetivo relatar a construção de um terrário por estudantes do $7^{\circ}$ ano do Ensino Fundamental de uma escola pública mato-grossense e as suas percepções sobre as relações ecológicas possibilitadas pela atividade e os cuidados necessários com o meio ambiente para minimizar os impactos ambientais provocados pelas atividades humanas.

\section{EDUCAÇÃO AMBIENTAL E O DESENVOLVIMENTO DE TERRÁRIOS}

No Brasil, a EA vem sofrendo mudanças desde sua implantação modificando-se ao longo do tempo. Atualmente passou a ter uma interface voltada ao desenvolvimento social e econômico da sociedade brasileira de acordo com a política nacional, expressa na Lei (9.795/99), em seu Art. $1^{\circ}$ diz que: 
Entende-se por educação ambiental os processos por meio dos quais os indivíduos e a coletividade constroem valores sociais, conhecimentos, habilidades, atitudes e competências voltadas para a conservação do meio ambiente, bem de uso comum do povo, essencial a sadia qualidade de vida sustentável.

Em outras palavras, a EA abrange todos os indivíduos inseridos na sociedade com vistas a educar para a construção de uma nova postura perante $o$ meio ambiente, afim de promover a conservação ambiental para o bem comum. Desse modo, se faz necessário trazer este debate para o âmbito escolar, pois a escola tem a capacidade de enredar diversos sujeitos direta e indiretamente.

A escola tem um papel preponderante para a adoção de novos hábitos sejam vivenciados e repassados para os demais membros que compõem a comunidade escolar. Em seus estudos, (CARNEIRO,2011, p. 142) afirma que: "A escola como espaço de convivência e modelo de relações, propõe no diaa-dia as situações para que a comunidade escolar viva essa possibilidade de um planeta sustentável". Ao observar por este prisma temos a escola como um veículo de informação capaz de conceituar e promover a aplicabilidade dos conceitos não apenas em seu espaço físico, mas para além dele de forma ampla e responsável uma vez que a preocupação com o meio ambiente perpassa o âmbito escolar.

Consideramos que o papel da escola é fundamental para a sociedade como "forma principal e dominante de educação" (SAVIANI, 2015, p. 35). Acreditamos que são inúmeras as razões para inserir a EA no currículo escolar, pois a escola busca educação integral para que o estudante possa exercer a cidadania como um sujeito crítico e atuante na sociedade.

Em perspectiva similar, Sorrentino et al. (2005, p. 287) afirmam que: "Educação ambiental, em específico, ao educar para a cidadania, pode construir a possibilidade da ação política, no sentido de contribuir para formar uma coletividade que é responsável pelo mundo que habita". Ou seja, a EA precisa se pautar na coletividade, no sentido de provocar a sociedade para a construção de políticas públicas voltadas a sensibilização acerca das atitudes de cada indivíduo e o reflexo das mesmas na perspectiva global tornando-o um agente ativo neste processo de ensino e aprendizagem.

Todavia, ainda de acordo com Sorrentino et al. (2005), quando há a interação entre o objeto de estudo e o estudante subsidiado para além do desenvolvimento das competências, a sua autonomia perante $\mathrm{o}$ ato de aprender, a escola de educação básica tem um papel preponderante na formação da sociedade, já que por ela passam todos os sujeitos que constituem a sociedade. Assim, a escola pode ser um agente capaz de promover a transformação social, principalmente quando envolve uma temática que é de interesse comum como é o caso das questões ambientais. 
Sabemos que a EA perpassa todas as áreas de conhecimento, por isso existe uma gama de estratégias metodológicas a serem exploradas que podem ser adotadas. Neste caso, é importante observar o público a ser atendido e os resultados a serem alcançados. Diante desta perspectiva, a EA pode ser efetivada em todas as unidades de ensino voltada para a construção de uma sociedade crítica e capaz de compreender a sua relevância para a manutenção dos sistemas biológicos.

$\mathrm{Na}$ área de ciências da natureza existem diversas estratégias metodológicas que podem ser exploradas conforme destaca os Parâmetros Curriculares Nacionais (BRASIL, 2006, p. 32);

Um vaso de planta, um aquário ou um terrário feito em uma garrafa podem permitir o desenvolvimento de múltiplos conteúdos sem grandes gastos de dinheiro ou de tempo. Mais do que contornar uma situação desfavorável, tais práticas permitem ao aluno um novo olhar sobre o corriqueiro

Em perspectiva similar, Botelho (2008) define o terrário como um dispositivo experimental que reproduz um ambiente natural. Também é possível considerar que esse experimento é constituído de diversas formas e que não segue padrão obrigatório, o que o torna uma maneira de explicitar aquilo que o estudante pretende estudar. Sendo assim, a construção de terrários é uma alternativa voltada ao ensino de Ciências Naturais motivando o estudante a ser um agente ativo diante do processo educativo.

Outra definição sobre os terrários foi feita por Rosa (2009, p. 88);

Os Terrários são apresentados como modelos de Ecossistemas terrestres e constituem-se de minilaboratórios práticos, através dos quais procura-se reproduzir as condições do meio ambiente. São montados em potes (caixas de vidro tipo aquário), onde são depositados cascalhos, areia, terra preta, pequenas plantas e animais (ex: tatuzinho do jardim, insetos, minhocas e caracóis), assim como um pequeno recipiente com água.

Diante dessa descrição, é possível compreender que a experiência da construção do terrário é uma estratégia metodológica que pode ser proposta a fim de buscar resultados significativos para as aulas de ciências da natureza. Nesse sentido, pode ir além do potencial pedagógico e despertar um dos principais fatores para que o processo de ensino aprendizagem seja exitoso, a motivação do estudante. Ao montar e escolher os elementos do terrário, o estudante passa a ter curiosidade acerca do tema e formular perguntas que ele mesmo responde ao longo da investigação.

Numa perspectiva freireana, as aulas devem ser um espaço livre que possibilite ao estudante encontrar as respostas aos próprios questionamentos 
e ao professor ser um mediador atento as perspectivas do estudante em uma dialética em que professor e estudante possuem uma interligação com o conhecimento. Em um de seus conhecidos livros, Freire (1996, p. 58) ressalta que: "A boniteza de ser gente se acha, entre outras coisas, nessa possibilidade e nesse dever de brigar. Saber que devo respeito à autonomia e à identidade do educando exige de mim uma prática em tudo coerente com este saber". Assim, entendemos que o processo educativo deve ser uma troca na qual professor e estudante construam juntos o caminho a ser percorrido.

A escolha das atividades deve permitir que professor e estudante aprendam e ensinem mutuamente, o que confirma o pensamento de Alves (1984, p. 38), que ressalta: “O seu saber é um pássaro engaiolado, que pula de poleiro a poleiro, e que você leva para onde quer. Mas dos sonhos saem pássaros selvagens, que nenhuma educação pode domesticar".

Devido à complexidade dos conceitos e termos taxonômicos, muitas vezes a disciplina de Ciências Naturais se apresenta ao estudante como complexa. No entanto, ao trazer estratégias metodológicas com abordagens práticas é possível livrar o saber da gaiola e aproximá-lo do estudante. Conforme Alves (1984), a escola não deve se preocupar em ensinar a marcha, mas sim garantir que nunca o estudante esqueça de saltar.

Outro aspecto importante a ser considerado com a inserção do terrário como estratégia metodológica, é o fato dos inúmeros questionamentos feitos pelos estudantes entre a turma e para o professor. Deste modo, é importante a intervenção do professor no sentido de direcionar os questionamentos, de provocar os estudantes a buscar as próprias respostas. Freire e Faundez (1985) alertam que ao ensinar, muitas vezes os envolvidos esqueceram das perguntas, tanto o professor quanto os estudantes, ou seja, é preciso retomar o espírito investigativo da aprendizagem.

As perguntas referentes ao terrário conduzem o estudante a compreensão sobre o meio ambiente, ou seja, a escolha desse dispositivo experimental para contextualizar o meio ambiente é uma prática relevante. Odum (1988) aponta que por meio da teoria dos ecossistemas, temos princípios relacionados a um ciclo de energia, os ciclos biogeoquímicos, cadeia alimentar. Fatores evidenciado em um terrário, pois para sua construção é necessário a utilização de seres bióticos e abióticos e eles são postos em um ambiente fechado onde não existe troca com o meio externo, o que permite estabelecer relações ecológicas entre os elementos que compõem o microambiente.

Outro aspecto importante é que o terrário se constitui em uma estratégia metodológica de fácil acesso. Os elementos utilizados na construção estão disponíveis no cotidiano e após sua montagem o estudante precisa fazer as observações acerca das mudanças que ocorreram no microambiente. Segundo Benetti (2012), a montagem do terrário, nas aulas práticas de ciências, possibilita ilustrar um ecossistema em miniatura. 


\section{PROCEDIMENTOS METODOLÓGICOS}

$\mathrm{O}$ presente estudo configura-se como um relato de experiência, descritivo e exploratório, cuja abordagem de análise é qualitativa, mesmo que utilizando de dados numéricos. Para Medeiros (1997), os relatos de experiência são textos descritivos, que possuem a finalidade de evidenciar características de uma determinada situação vivenciada, sem ter obrigatoriamente um rigor metodológico extremamente formal para apresentar seus resultados.

Segundo Gil (2010), um estudo descritivo e exploratório pode ser compreendido como sendo aquele que tem por finalidade levantar características de populações, fenômenos ou experiências, a exemplo desse momento formativo.

A situação relatada ocorreu em uma escola pública mato-grossense, localizada em Vila Rica/MT, município que fica distante $1.300 \mathrm{Km}$ aproximadamente da capital Cuiabá/MT. Sua realização ocorreu no segundo semestre de 2019. O público envolvido foi constituído por 28 estudantes do $7^{\circ}$ ano do Ensino Fundamental, devidamente matriculados no turno vespertino.

Após apresentação do objetivo da pesquisa, a gestão da escola emitiu Carta de Anuência autorizando a realização da pesquisa. Cabe ressaltar que todos os pais dos estudantes aceitaram e assinaram um termo no ato da matrícula no qual emitem o consentimento para que seus filhos participem de todas as atividades da escola, inclusive de pesquisas com finalidade educativa.

A intervenção pedagógica teve o intuito de desenvolver por meio da construção de um terrário uma estratégia de ensino alternativa e lúdica que busca estimular a criatividade, pois permite a materialização de um ou conceito de forma que possa ser comparada com a realidade. Além disso, acredita-se que a construção do terrário auxiliou nos estudos sobre ecologia ao proporcionar que os estudantes ampliassem conhecimento acerca da dinâmica ambiental bem como as diversas relações ecológicas existentes entre o meio biótico e abiótico.

A atividade relatada aconteceu no percurso de 04 aulas dentro da sala, além dos dias que observariam em casa, entorno de duas semanas. Nas duas primeiras aulas os estudantes tiveram acesso à teoria a respeito de ecologia, pelo uso do livro didático, e receberam as orientações para o desenvolvimento da atividade prática que consistiu na elaboração do terrário. Foram mencionados os materiais de uso obrigatório: pedrinhas, areia, solo, plantas, um frasco fechado e água para regar, além dos itens decorativos e animais de uso opcional.

Os estudantes também ficaram cientes que após a construção do terrário, o mesmo deveria ser observado por no mínimo 10 dias e todas as observações deveriam ser anotadas para compor o relatório e que no dia da entrega seria feita a socialização oral e recolhido o relatório. Também ficou combinado que o terrário seria exposto para a comunidade escolar do turno vespertino. Para tanto, foi reforçado que haveria exposição oral em dois momentos, sendo um 
na sala de aula para a professora e colegas e, outro uma exposição para todo público da escola.

Ao final das apresentações os estudantes foram submetidos a um questionário com 12 perguntas, sendo 9 delas abertas e 3 perguntas fechadas. Para garantir o anonimato dos envolvidos, as respostas foram agrupadas por semelhança, de maneira a não identificar o estudante respondente.

A metodologia utilizada para analisar os dados foi a análise de conteúdo, do tipo temática e frequencial (BARDIN, 2012). Para a autora, existem duas maneiras de categorizar as respostas dos investigados: categorias a priori (com categorias definidas ou pré-estabelecidas), geralmente utilizadas em questionários fechados, e categorias emergentes (construídas a partir dos dados), geralmente identificadas em questões abertas. Os dados foram organizados em três categorias: concepções conceituais sobre terrário, avaliação da atividade realizada e suas percepções sobre as ações humanas frente a natureza. Cabe ressaltar que outro pesquisador poderia identificar outras categorias.

\section{RESULTADOS E DISCUSSÃO}

Nas duas últimas aulas, transcorrido os dias de observações, aconteceu a culminância e socialização da atividade em forma de seminário onde os estudantes fizeram a exposição dos respectivos temas e em seguida preencheram o questionário com a avaliação do trabalho. A Figura 1 ilustra alguns terrários que foram construídos.

Figura 1 -Terrários construídos pelos estudantes do $7^{\circ}$ ano do Ensino Fundamental

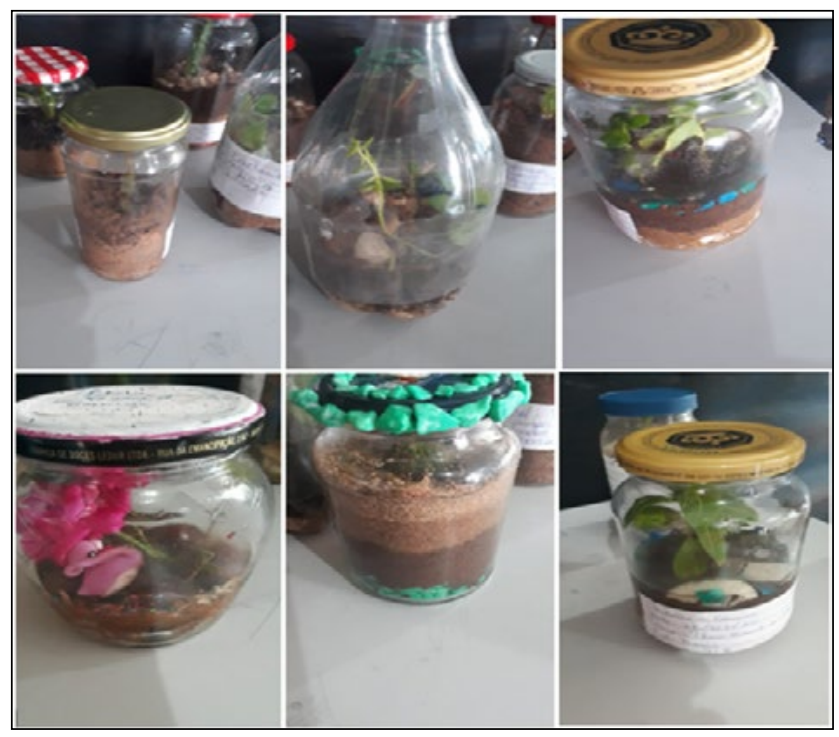

Fonte: Dados coletados na pesquisa (2019). 
Os terrários produzidos pelos estudantes foram construídos de acordo com a percepção deles sobre o assunto e de acordo com a realidade que vivenciam, ou seja, utilizaram os materiais que haviam disponíveis em casa, no jardim e no entorno da residência para representar o que entenderam. Todos os terrários apresentaram os elementos básicos exigidos tais como, frasco fechado, pedras, areia, solo e plantas e os demais elementos ficaram a critérios dos estudantes e muitos usaram a criatividade para enfeitá-los, deixando evidente que a atividade foi prazerosa, pois, além do "aprendizado do rigor, você desaprendeu o fascínio do ousar" (ALVES, 1988, p. 76).

Ao construírem os terrários, os estudantes ilustraram todo um ecossistema, mesmo que em tamanho menor, o que certamente potencializou a compreensão sobre o assunto e dinamizou as aulas de ciências, por meio dessa atividade prática como indicou Benetti (2012). A montagem do terrário permite ilustrar e compreender os elementos e as mudanças que ocorreram no microambiente.

Dos dados obtidos pelo questionário, a primeira categoria (concepções conceituais sobre terrário) foi identificada a partir das respostas fornecidas as 7 primeiras perguntas, que investigaram: definição de terrário, importância dos mesmos, se consideram o terrário um ecossistema, materiais utilizados, identificação dos elementos em biológicos e físicos, papel desempenhado pelas pedrinhas e areia, além do comportamento da água presente no terrário.

Sobre a definição do assunto para 13 estudantes "o terrário é um ambiente", 9 estudantes o definiram como "um pequeno ecossistema", 3 deles definiram como "um microambiente" e outros 3 estudantes não responderam. Referente a importância do terrário, 18 estudantes afirmaram que "serve para observar a natureza", já 6 estudantes acreditam que "serve para compreender as relações ecológicas", e outros 4 estudantes mencionaram que "serve para observar o ciclo da água". Quando questionados se consideram o terrário como um ecossistema 20 estudantes afirmaram que sim, outros 7 estudantes disseram que não sabem e apenas um deles afirmou que não é.

De acordo com as repostas, é possível afirmar que o conceito de terrário foi compreendido pelos estudantes, visto que conseguiram compreender o conceito de terrário e assimilar ao conceito de meio ambiente. A atividade relatada confirma as palavras de Rosa (2009) sobre o conceito de ecossistema, que está ancorado em dois elementos estabelecendo relações de interdependências entre os elementos bióticos e abióticos em um ambiente fechado, no qual ocorre o ciclo de energia que irá regular o ciclo fechado da matéria. É perceptível que a experiência veio contemplar os objetivos esperados, nesse sentido, é possível afirmar que o processo educativo requer práticas voltadas a autonomia do estudante.

Sobre os materiais utilizados na construção dos terrários, 12 estudantes utilizaram areia, pedrinhas, terra, plantas e pequenos animais, outros 10 utilizaram apenas areia, pedras, terra e plantas e outros 6 estudantes 
utilizaram areia, pedrinhas, terra, animais e enfeites. Percebe-se que nem todos descreveram os materiais de uso obrigatório para a construção de um terrário, que são: pedrinhas, areia, solo, plantas, um frasco fechado e água para regar, sendo opcional o uso de animais e/ou itens decorativos. O Quadro 1 apresenta as respostas dos estudantes ao serem questionados sobre a classificação dos elementos constitutivos do terrário em físicos ou biológicos.

Quadro 1 - Classificação dos elementos constitutivos do terrário

\begin{tabular}{|c|c|c|}
\hline Elementos & Físico & Biológico \\
\hline Água & 21 & 07 \\
\hline Solo & 28 & 0 \\
\hline Plantas & 01 & 27 \\
\hline Animais & 02 & 26 \\
\hline Areia & 26 & 02 \\
\hline
\end{tabular}

Fonte: Dados coletados na pesquisa (2019).

Isso mostra que, embora muitos estudantes tenham compreendido os conceitos físicos e biológicos, ainda existe uma pequena parcela que não conseguiu distinguir um do outro. Isso ficou evidenciados nas respostas dando o indicativo para o professor retomar a explicação dos conceitos para que possam ser assimilados pelos estudantes contemplando as múltiplas inteligências e o tempo de aprendizado de cada estudante.

Ao serem questionados sobre o papel das pedrinhas e da areia no terrário, os estudantes foram unânimes em mencionar que esses dois elementos servem para drenar a água. Além de identificar essa utilidade, boa parte deles justificou a importância destes elementos, uma vez que eles estavam entre os itens obrigatórios para construção do terrário.

Sobre o papel desempenhado pela água no terrário, as respostas foram igualmente unânimes "serve para hidratar a planta." Referente ao comportamento da água no terrário, os respondentes foram enfáticos em mencionar que a água percorre um ciclo, o que torna o sistema equilibrado e com possibilidade de vida.

Conforme defendido na teoria dos ecossistemas, um aspecto primordial de ser constatado na observação de um terrário são as transformações que ocorrem nesse ambiente fechado, dentre elas os ciclos de energia e os ciclos biogeoquímicos, em especial o da água Odum (1988). Outro aspecto que pode ser explorado é a utilização de seres bióticos e abióticos e eles são postos no terrário, que é um ambiente fechado e permite o estabelecimento de relações entre eles.

A segunda categoria (avaliação da atividade realizada), foi identificada a partir das respostas fornecidas a 3 outros questionamentos, que indagaram sobre a satisfação em desenvolver sua atividade, contribuições para aprender 
ecologia e as dificuldades encontradas para construir o terrário. Sobre o nível de satisfação ao realizar a atividade proposta, 18 estudantes atribuíram nota 5 e outros 10 estudantes atribuíram nota 4 . Em uma escala.na qual a nota máxima era 5 , correspondente a (ótimo), em seguida decrescia 4 (muito Bom), 3 (bom), 2 (regular) e 1 (ruim).

A atividade prática agrada aos estudantes, pois faz com que os estudantes deixem de lado a rotina, muitas vezes cansativas principalmente para faixa etária entre 11 e 12 anos e se envolvam com os conteúdos de uma forma mais efetiva. Nas palavras de Alves (2001 p. 24), o professor precisa deixar claro que existem respostas certas, mas não retirar o prazer do estudante de investigar: "E, com isto, ao aprender as respostas certas, os estudantes desaprendem a arte de se aventurar e de errar, sem saber que, para uma resposta certa, milhares de tentativas erradas devem ser feitas."

Ao serem questionados sobre a importância dessa atividade para compreender ecologia, todos os estudantes foram unânimes em responder que sim, pois foi possível perceber na prática aquilo que tinham estudado no livro didático, ou seja, de maneira teórica. Aliar teoria e prática significa as aulas e corrobora aos estudos de Carneiro (2011), que acredita ser a escola o espaço propício para possibilitar o estabelecimento de relações entre os elementos constitutivos do planeta para levar a uma convivência harmônica e sustentável.

A Figura 2 ilustra as principais dificuldades encontradas pelos estudantes ao desenvolverem a atividade de construção do terrário.

Figura 2 -Dificuldades mencionadas pelos estudantes

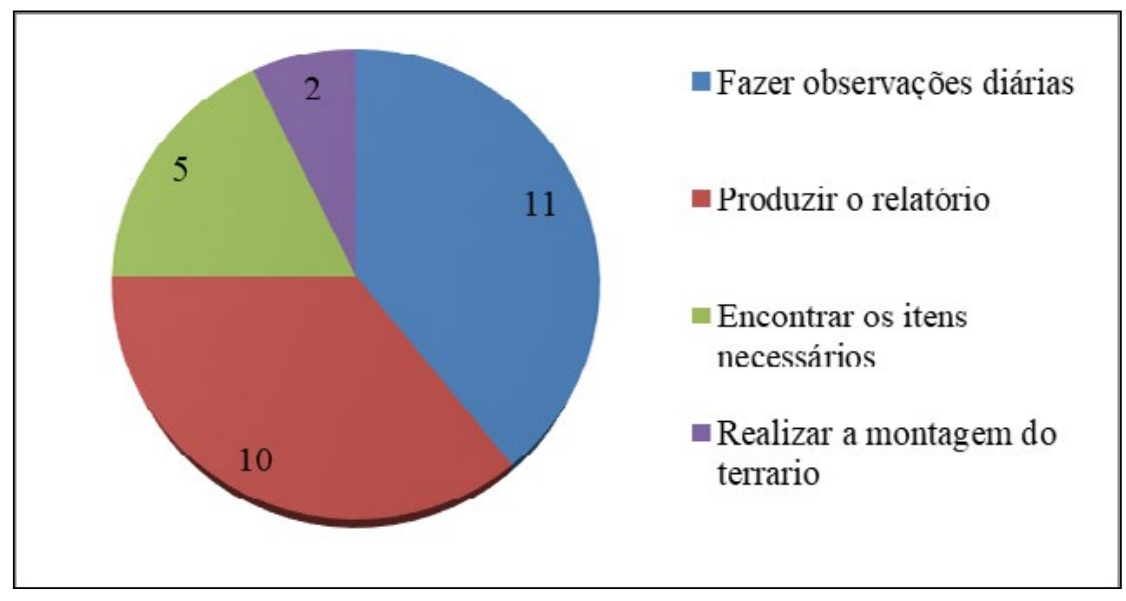

Fonte: Dados coletados na pesquisa (2019).

Os maiores desafios que os estudantes destacaram foram o de estabelecer a rotina na observação diária, seguida pela produção de relatório, também em encontrar os materiais. Já a montagem do terrário foi etapa mais bem aceita 
pelos estudantes. Uma importante observação que o papel da escola é de inserir a pesquisa na Educação Básica, como Bizzo (2009, p. 16) destaca: “[...] é reconhecer a real possibilidade de entender o conhecimento científico e a sua importância na formação dos nossos alunos uma vez que ele pode contribuir efetivamente para a ampliação de sua capacidade".

A terceira e última categoria (avaliação da atividade realizada), foi identificada a partir das respostas fornecidas aos dois últimos questionamentos: Após realizada a experiência do terrário, como você avalia a interferência do homem no meio ambiente? Quais atividades humanas provocam maiores impactos ambientais? A Figura 3 ilustra os aspectos da ação humana na natureza, ou seja, como consideram que o homem interfere no meio ambiente.

Figura 3 -Interferência do homem no meio ambiente

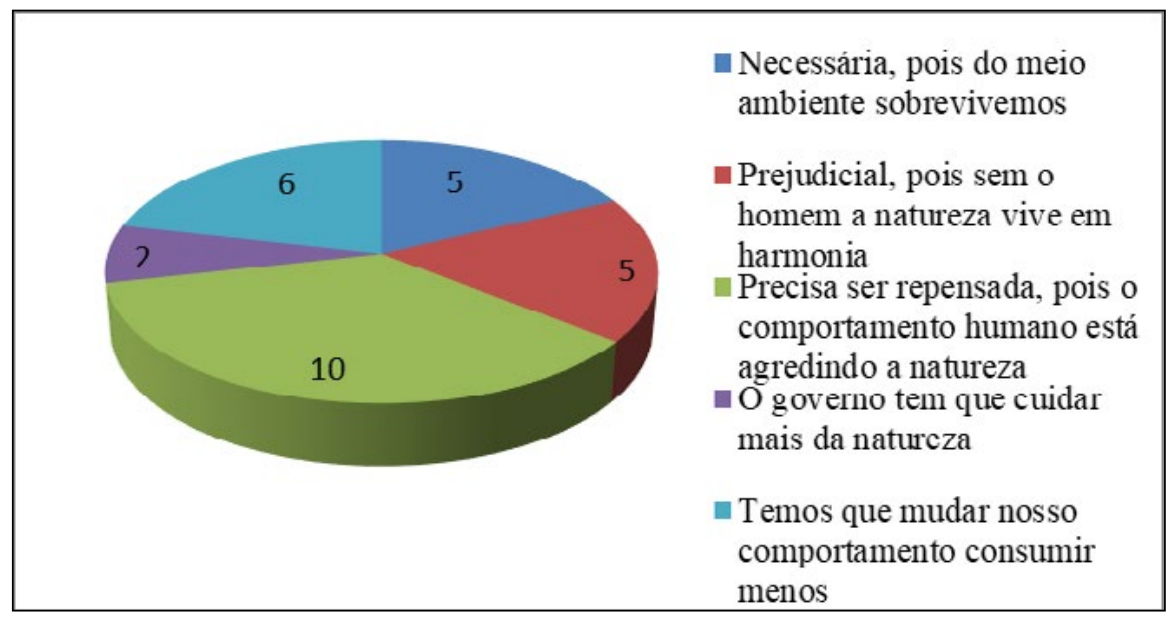

Fonte: Dados coletados na pesquisa (2019).

Os estudantes demonstraram que compreenderam que as ações antrópicas precisam ser repensadas de forma a minimizar os impactos ambientais, pois da forma com que as pessoas agem frente ao meio ambiente, elas estão comprometendo a existência da vida na terra. De acordo com os Parâmetros Curriculares Nacionais, a disciplina de Ciências Naturais é de extrema relevância para que o estudante compreenda a relação do homem com a natureza:

Em Ciências Naturais, o desenvolvimento de posturas e valores envolve muitos aspectos da vida social, da cultura do sistema produtivo e das relações entre o ser humano e a natureza. Incentivo às atitudes de curiosidade, de persistência na busca e compreensão das informações, de preservação do ambiente e sua apreciação estética, de apreço e respeito à individualidade e à coletividade tem lugar no processo de ensino e aprendizagem (BRASIL, 1998, p. 30). 
Dado o exposto, as atividades precisam se voltar a construção de um pensamento coletivo em relação as ações acerca do meio ambiente e também suas consequências. Isso também reforça que as aulas de ciências são fundamentais para o estudante ter uma visão holística do planeta e suas ações. A Figura 4 ilustra o posicionamento dos estudantes sobre os impactos ambientais que provocam devido a maneira de vida que adotam.

Figura 4 -Impactos ambientais provocados pelas ações humanas

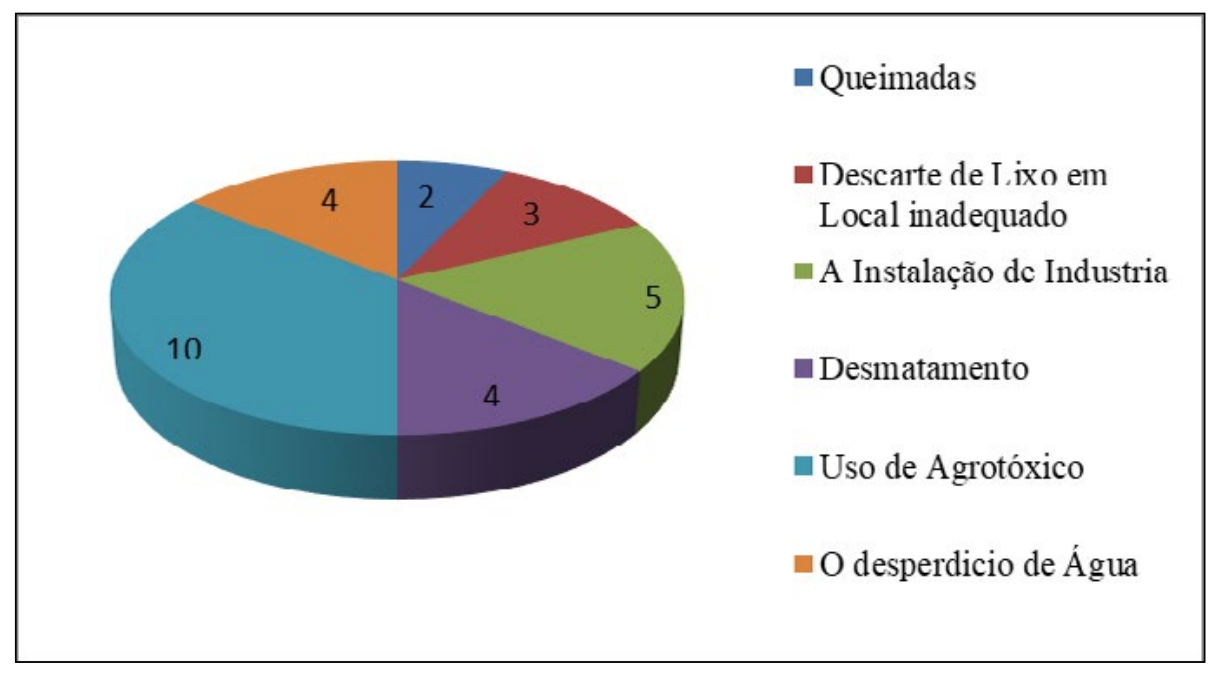

Fonte: Dados coletados na pesquisa (2019).

Os estudantes demonstraram que são capazes de identificar as ações humanas capazes de promover impactos ambientais e, nesse sentido, a escola faz seu papel ao propor a educação ambiental voltada para as nossas práticas cotidianas. Isso corrobora com Freire (1980, p. 39), ao afirmar que "é preciso que a educação esteja - em seu conteúdo, programas e métodos - adaptada ao fim que se persegue: permitir ao homem chegar a ser sujeito, construir-se como pessoa, transformar o mundo, estabelecer com os outros homens relações de reciprocidade".

Assim sendo, a EA precisa ser um processo de sensibilização que aponte um novo caminho, voltado para a tomada de decisões de cada indivíduo. Considerando sua responsabilidade social. Por meio de ações práticas o estudante consegue enxergar a importância de suas atitudes.

\section{CONSIDERAÇÕES FINAIS}

A realização dessa atividade possibilitou relatar a construção de terrários como estratégia didática para o ensino de Ciências Naturais e identificar as percepções dos estudantes dessa turma do $7^{\circ}$ ano do Ensino Fundamental, 
referente ao conceito e elementos envolvidos no terrário e suas avaliações quanto a atividade realizada. Suas percepções sobre a relações do homem e a natureza.

Acreditamos no potencial da educação voltada a sensibilização da sociedade. Uma vez que não é por falta de informação que o meio ambiente é destruído e sim pela falta de conhecimento. As atitudes impensadas em relação ao meio ambiente acarretam em graves consequências ao planeta. Entendemos que ao desmatar, queimar, poluir, utilizar ou desperdiçar os recursos naturais, são evidências de um legado cultural, ou seja, cada ser humano está mostrando o que aprendeu ao longo de sua história, a cultura que recebeu do seu povo. Na perspectiva Freireana o ser humano é um ser cultural.

Portanto, é fundamental repensar as aulas propondo atividades práticas voltadas ao meio ambiente onde seja possível que cada estudante construa seus próprios conceitos. A construção do terrário possibilitou que os estudantes envolvidos externassem suas percepções sobre o assunto e estabelecessem relações que remetem os cuidados necessários com o meio ambiente. É necessário que a educação seja um retrovisor possibilitando a mudança de hábitos. Para que possamos construir uma nova realidade em função da coletividade por meio de ações que visam a sustentabilidade.

\section{REFERÊNCIAS}

ALVES, Rubem. A alegria de ensinar. 6. edição. - São Paulo: Papirus, 2001

BARDIN, Laurence. Análise de conteúdo. São Paulo: Edições 70, 2012.

BENETTI. Ana Carolina Meirelles. Uma Proposta para Trabalhar Conscientização Ambiental com Alunos do Ensino Fundamental. Universidade do Vale do Paraíba. São José dos Campos/SP, 2012.

BIZZO, Nélio. Como eu ensino: Pensamento Científico, a Natureza da Ciência no Ensino Fundamental. São Paulo: Melhoramentos, 2008.

BOTELHO, Lazara Aparecida. O Terrário como instrumento organizador da aprendizagem em Ciências do $9^{\circ}$ ano. Programa de Desenvolvimento Educacional PDE. Curitiba - Paraná, 2008.

BRASIL. Secretaria de Educação Fundamental. Parâmetros Curriculares Nacionais: Meio Ambiente Saúde/ Ciências Naturais. Secretaria de Educação Fundamental. Brasil: 1997.

Secretaria de Educação Fundamental. Parâmetros curriculares nacionais: Ciências Naturais/Secretaria de Educação Fundamental. Brasília: MEC /SEF, 1998.

CARNEIRO, Silvia Lignon. Escola Amigos do Verde: resiliência, amorosidade e ciência para a sustentabilidade. 1. ed. Porto Alegre: Armazém Digital, 2011. 
IBGE. Contas regionais do Brasil: 2010-2014 / IBGE, Coordenação de Contas Nacionais. - Rio de Janeiro: IBGE, 2016.

DELIZOICOV, Demétrio. ANGOTTI, José André. PERNANBUCO, Marta Maria. Ensino de Ciências fundamentais e métodos. 3 ed. - São Pulo: Cortez, 2009.

GIL, Antônio Carlos. Como elaborar projetos de pesquisa. 5. ed. São Paulo-SP: Atlas, 2010.

GRZEBIELUKA, Douglas; KUBIAK, Izete e SCHILLERREMO, Adriane. Educação Ambiental: A importância deste debate na Educação Infantil. Revista Monografias Ambientais - REMOA Revista do Centro das Ciências Naturais e Exatas - UFSM, Santa Maria.13, n.5, dez. 2014

FREIRE, Paulo; FAUNDEZ, Antonio. Por uma Pedagogia da Pergunta. - Rio de Janeiro: Paz e Terra, 1985.

FREIRE, Paulo. Pedagogia da autonomia: saberes necessários à prática educativa. São Paulo: Paz e Terra, 1996.

FREIRE, Paulo. Conscientização: teoria e prática da libertação - uma introdução ao pensamento de Paulo Freire. 4. ed. São Paulo: Moraes, 1980. 102 p.

LEONARD, Annie. A História das Coisas da Natureza ao Lixo o que Acontece com Tudo que consumimos. Tradução Heloisa Mourão. Rio de Janeiro, Zahar. 2011.

MEDEIROS, João Bosco. Redação Científica: a prática de fichamentos, resumos e resenhas. 3. ed. São Paulo-SP: Atlas, 1997.

ODUM, EugèneP. Ecologia. Rio de Janeiro: Ed. Guanabara. 1988.

RICKLEFS, Robert. A economia da natureza / Robert Ricklefs, Rick Relyea; revisão técnica Cecília Bueno; Tradução Ana Cláudia de Macêdo Vieira... [etal.]. - 7. ed. - Rio de Janeiro: Guanabara Koogan, 2016.

ROSA, Rosane Teresinha Nascimento da. Terrário no ensino de ecossistemas terrestres e teoria ecológica. Revista Brasileira de Educação Científica e Tecnológica. v. 2, n. 1, p. 87- 104, jan/abr. 2009.

SAVIANI, Demerval. O conceito dialético de mediação na pedagogia históricocrítica em intermediação com a psicologia histórico-cultural. Germinal: marxismo e educação em debate, Salvador, v. 7, n. 1, p. 26-43, 2015.

SORRENTINO, Marcos; TRAJBER, Rachel; MENDONCA, Patrícia e FERRARO JUNIOR, Luiz Antonio. Educação ambiental como política pública. Educação \& Pesquisa [online]., v.31, n.2, p.285-299, 2005.

WEISMAN,Alan. Contagem Regressiva: A Nossa última e melhor esperança para um futuro na Terra. Tradução de Alice Klesck. São Paulo: LeYa, 2014. 